\title{
VISITA AO MUSEU DE LOUCURA: UMA EXPERIÊNCIA DE APRENDIZAGEM SOBRE A REFORMA PSIQUIÁTRICA
}

\author{
VISITING THE MUSEUM OF MADNESS: THE EXPERIENCE OF LEARNING ABOUT THE PSYCHIATRIC \\ REFORM
}

\section{VISITA AL MUSEO DE LA LOCURA: UNA EXPERIENCIA DE APRENDIZAJE SOBRE LA REFORMA PSIQUIÁTRICA}

\section{Nadja Cristiane Lappann Botti ${ }^{1}$, Eline Mascarenhas Cotta ${ }^{2}$, Fabiano de Almeida Célio ${ }^{3}$}

RESUMO: O Museu da Loucura de uma cidade do interior do estado de Minas Gerais é um espaço onde arte, história e memória revelam as diferenças da psiquiatria do início do século passado e a abordagem atual. Foi realizado um estudo qualitativo com 39 acadêmicos de Enfermagem, objetivando identificar o significado da visita ao Museu da Loucura para os acadêmicos. O referencial metodológico foi o Discurso do Sujeito Coletivo e o teórico a Reforma Psiquiátrica. Os dados mostram o significado da visita como vivência potencial de aprendizagem das dimensões da Reforma Psiquiátrica ao conduzir o aluno a questionar as práticas e saberes da Psiquiatria na lógica asilar.

PALAVRAS-CHAVE: Educação em Enfermagem; Saúde Mental; Reforma dos Serviços de Saúde.

ABSTRACT: The Museum of Madness in the landscape of the Minas Gerais State is a place where art, history and memory disclose the differences about the Psychiatry approach since the beginning of the last century till nowadays. A qualitative study with 39 nursing undergraduate students was developed, aiming to identify the meaning of the visit to the Museum of Madness. The methodological referential was the Collective Subject Discourse and the theoretical the Brazilian Psychiatric Reform. The data shows the meaning of the visit as potential experience of learning of the dimensions of the Psychiatric Reform when leads the student to question the practice and to know of Psychiatry in the asylum perspective.

KEY WORDS: Nursing Education; Mental Health; Health Care Reform.

RESUMEN: El Museo de la Locura en el estado de Minas Gerais es un local donde arte, historia y memoria revelan las diferencias de la abordaje de Psiquiatría del principio del siglo pasado hasta la actualidad. Fue realizado un estudio cualitativo con 39 estudiantes de graduación en Enfermería, objetivando identificar el significado de la visita al Museo de la Locura. Lo referencial metodológico fue el Discurso del Sujeto Colectivo y el teórico la Reforma Psiquiátrica Brasileña. Los datos demuestran el significado de la visita como experiencia potencial de aprendizaje de las dimensiones de la reforma psiquiátrica al conducir el académico a cuestionar la práctica y saber de la Psiquiatría en la perspectiva asilar.

PALABRAS-CLAVE: Educación en Enfermería; Salud Mental; Reforma en Atención de la Salud.

1 Enfermeira, Psicóloga, Dra. em Enfermagem Psiquiátrica. Professor Adjunto III da PUC Minas - Betim. Belo Horizonte, Minas Gerais.

E-mail nadjaclb@terra.com.br

2 Acadêmica do $3^{\circ}$ período do Curso de Graduação em Enfermagem da PUC Minas - Betim - E-mail: eline sl@yahoo.com.b

3 Acadêmico do $3^{\circ}$ período do Curso de Graduação em Enfermagem da PUC Minas - Betim - E-mail: maitiz@gmail.com 


\section{INTRODUÇÃO}

Segundo CHAUİ (1994) os antigos gregos consideravam a memória uma identidade sobrenatural ou divina. A deusa Mnemosyn (memória), mãe das musas, era quem protegia as Artes e a História, ela dava aos poetas e adivinhos o poder de voltar ao passado e de lembrá-lo para a coletividade. Para os antigos romanos, a memória ainda possuía outra função, era considerada essencial para o aprendizado.

A constituição histórica do conceito de loucura começa com a história da espécie humana e a sintomatologia apresenta-se ligada à vida social, assim a definição de loucura sofreu modificações ao longo do tempo (JORGE \& SILVA, 2000). A partir do século XIX, tem-se início a assistência psiquiátrica brasileira, centrada no paradigma asilar.

Historicamente a Reforma Psiquiátrica surgiu para questionar os saberes e práticas profissionais propostas pelo paradigma asilar, pautados na tutela, segregação e exclusão social (AMARANTE, 1997). A reforma da atenção ao portador de sofrimento mental é hoje uma realidade incontestável no Brasil.

Considerando o movimento da Reforma Psiquiátrica em curso, é importante ressaltar que a mudança do modelo de assistência em Saúde Mental não implica apenas em implantação de Serviços Substitutivos em Saúde Mental, mas torna-se imprescindível uma modificação na prática profissional pautado no modelo psicossocial, um paradigma das práticas em Saúde Mental substitutivas ao modelo asilar (COSTA-ROSA, 2000).

SILVA FILHO \& LEIBING (1999) colocam que um dos desafios a serem enfrentados pelo movimento da Reforma Psiquiátrica diz respeito à formação dos recursos humanos da área da saúde para a construção de um novo sistema de atenção em Saúde Mental. Neste sentido o ensino da Saúde Mental e Psiquiatria do Curso de Graduação em Enfermagem da PUC Minas - Betim visa contribuir na formação do profissional enfermeiro a partir dos pressupostos da Reforma Psiquiátrica Brasileira (AMARANTE, 1997) e do Paradigma Psicossocial (COSTA-ROSA, 2000).

A partir da aprovação da Lei de Diretrizes e Bases da Educação (LDB), Lei n. 9394/96 os projetos políticos pedagógicos dos Cursos de Enfermagem possibilitaram maior flexibilização dos currículos, e, nesse sentido, foi preciso ousar propondo e construindo experiências acadêmicas criativas e inovadoras. Um outro aspecto que merece referência diz respeito ao ensino por competência, que privilegia pensar criticamente a realidade da saúde, com vistas a transformá-la. $\mathrm{E}$ assim sendo, ressalta a importância e uma proposta metodológica de ensino que trabalhe na perspectiva do paradigma açãoreflexão-ação (GERMANO, 2003).
Por tais motivos é proposta a visita dos acadêmicos de enfermagem da Pontifícia Universidade Católica de Minas ao Museu da Loucura. Inaugurado no dia 16 de agosto de 1996, o Museu da Loucura resgata a memória da Psiquiatria, através de objetos, documentos, fotografias, sons e imagens.

\section{OBJETIVOS}

O objetivo deste estudo foi identificar o significado da visita ao Museu da Loucura para os acadêmicos do $4^{\circ}$ período do Curso de graduação em Enfermagem, com vistas a conhecer possibilidades para o processo ensino aprendizagem na temática.

\section{REFERENCIAL TEÓRICO E METODOLÓGICO}

Por meio de MINAYO (1999) podemos entender a pesquisa como uma atividade básica da ciência na sua indagação da realidade. É a pesquisa que alimenta a atividade de ensino e a alimenta frente à realidade do mundo, assim, foi desenvolvido um estudo de natureza qualitativa através do referencial metodológico do Discurso do Sujeito Coletivo (DSC) proposto por LEFÈVRE \& LEFÈVRE (2000).

A investigação foi realizada com 39 acadêmicos do $4^{\circ}$ período do Curso de Graduação em Enfermagem. No transcorrer da disciplina de Saúde Mental e Psiquiatria (que apresenta carga horária total de 90 horas/aula, sendo 60 horas/aula teórica e 30 horas/aula prática) foi realizada uma visita ao Museu da Loucura em Barbacena, no Estado de Minas Gerais. A coleta de dados foi realizada com os acadêmicos que participaram da visita ao Museu da Loucura. A participação no estudo foi voluntária com consentimento livre e esclarecido. Os dados foram coletados por meio de entrevista estruturada respondida pelos acadêmicos após a visita ao Museu da Loucura.

Neste trabalho investigatório tivemos 3 questões norteadoras: (1) O que significou visitar o Museu da Loucura? (2) Qual a parte do Museu da Loucura visitada mais significativa para você? (3) Você recomendaria que outra pessoa visitasse 0 Museu da Loucura? Quem? Porquê?.

Os resultados foram construídos através do referencial metodológico do Discurso do Sujeito Coletivo (DSC) proposto por LEFÈVRE \& LEFÈVRE (2000). Segundo os autores a representação social é melhor visualizada neste modo discursivo, a medida em que ela se apresenta sob uma forma mais viva, real e direta de um discurso, pois esta é a forma como os indivíduos pensam. A construção do DSC, requer a utilização de figuras metodológicas elaboradas para organizar e tabular os discursos: a Idéia Central, as Expressões-Chave, as Ancoragens, e o Discurso do Sujeito Coletivo. 
O referencial teórico que sustenta a discussão foi o das dimensões do movimento da Reforma Psiquiátrica Brasileira, formulado por AMARANTE (1997).

\section{RESULTADOS E DISCUSSÃO}

AMARANTE (1997) propõe uma periodização da Reforma Psiquiátrica Brasileira composta de trajetórias. A primeira trajetória é definida como alternativa, que ocorre na década de 70 , quando surge o Movimento de Trabalhadores em Saúde Mental. O segundo momento da Reforma Psiquiátrica é o da trajetória sanitarista, iniciada nos primeiros anos da década de 80. A trajetória da desinstitucionalização é caracterizada, sobretudo, pelo surgimento de novos serviços, estratégias e conceitos em Saúde Mental, a partir da década de 90. Pode se entender, em suma que a Reforma Psiquiátrica trata-se de um processo que tem como princípios éticos a inclusão, a solidariedade e a cidadania.

A Reforma Psiquiátrica (AMARANTE, 1997) é um processo histórico de formulação crítica e prática que tem como objetivo e estratégia o questionamento e a elaboração de propostas de transformação do modelo clássico e do paradigma da Psiquiatria.

A Reforma Psiquiátrica é um processo em construção permanente, porque mudam os sujeitos, mudam os conceitos, mudam as práticas, mudam a história.

"A visita ao Museu da Loucura me fez repensar muitas coisas, sobre a minha vida, sobre o mundo, sobre as diferenças sociais que existem em nosso país e no mundo, significou uma mudança interior, me fez sensibilizar a respeito das pessoas que ali vivem, que ali viveram, uma reflexão e conscientização que os portadores de sofrimento mental tem direito a uma vida digna.

Na visita foi possível resgatar e ver a real história da assistência psiquiátrica, e entender como surgiu o tratamento psiquiátrico em Minas Gerais, as formas de tratamento adotadas, as condições vividas pelos internos e o pensamento da sociedade em relação aos "loucos", e assim, perceber a importância da luta antimanicomial.

Enfim, com a visita foi reafirmada a importância da visão crítica dos profissionais enfermeiros e de todos os enfermeiros em formação Pensar como eu posso contribuir para a efetiva socialização e cidadania dos portadores de sofrimento psíquico." (DSC9)

Neste sentido entende-se por Reforma Psiquiátrica um processo social complexo, pois é dinâmico, plural, articulado entre si por várias dimensões que são simultâneas e que se intercomunicam, que se retroalimentando, se complementam. Segundo AMARANTE (1997) as dimensões que permitem caracterizar a Reforma Psiquiátrica como processo social complexo são: dimensão teórico-conceitual, dimensão técnicoassistencial, dimensão jurídico-política e dimensão sócio-cultural.

\section{Dimensão teórico-conceitual}

No âmbito da Reforma Psiquiátrica, questionam-se os conceitos de doença mental, de normalidade, de cura, de periculosidade, a função terapêutica do hospital psiquiátrico e as relações entre os profissionais de saúde, a sociedade e os indivíduos considerados loucos. Segundo AMARANTE (1997) os hospitais psiquiátricos terminaram se transformando ao longo de sua existência em grandes "depósitos", lugares de isolamento e abandono de pessoas consideradas loucas, que não são respeitadas na sua diferença como sujeitos.

"A visita ao Museu da Loucura nos coloca diante de práticas ultrapassadas e cruéis, mostra um lugar de um século de sofrimento e exclusão onde milhares de pessoas já morreram vítimas do agravo da superlotação, abandono e descaso, mostra a psiquiatria da época e suas tentativas de lidar com os desvios humanos, com os seus métodos e sua mão de ferro para domesticar a loucura que orientavase pelo pressuposto isolar para cuidar.

De acordo com o que vimos na história da assistência psiquiátrica e podemos constatar na visita, os pacientes eram tratados de forma cruel como se representassem um grande risco para a sociedade, viviam em condições de higiene precária, tratados como se fossem animais. Hoje, já não se tratam os portadores de sofrimento mental como bichos, aprisionados em celas, com correntes amarradas nos pés." (DSC1)

No modelo psicossocial, o louco não é uma pessoa sem razão e sem juízo, um ser alienado, como visto na Psiquiatria Tradicional no modelo asilar. No entendimento da Reforma Psiquiátrica, o portador de sofrimento mental passa a ser considerado um sujeito, portanto, não se trata de enquadrar 0 portador de sofrimento mental aos padrões socialmente aceitos, mas pensar a cidadania em termos que considerem aspectos particulares e singulares de cada caso.

"A importância do Museu da Loucura é nos levar a pensar como tantos sofredores mentais foram marginalizados e excluídos e a partir dessa reflexão tentarmos ver o portador de uma outra maneira, porque o Museu da 
Loucura não deixa que a história da Psiquiatria em Minas e no Brasil fique arquivada num passado distante. É possível a desmistificação e a "quebra" do preconceito do louco. Permite imaginar um pouco da triste vida da qual os então considerados "loucos" foram submetidos, quantos estigmas, preconceitos, humilhações e falta de humanização, nos levando a refletir sobre quais são os verdadeiros cuidados que hoje estes precisam." (DSC2)

ROTELLI \& AMARANTE (1992) colocam que não basta substituir o manicômio por outros serviços, mas há necessidade de uma mudança radical que implica na construção de novas formas de entender, de lidar e de tratar a loucura.

\section{Dimensão técnico-assistencial}

Um dos objetivos específicos da Reforma Psiquiátrica é a substituição do modelo de atendimento centrado na hospitalização e no isolamento por uma atenção integrada ao indivíduo no seu local de domicílio, em seu território.

\begin{abstract}
“Não é possível ter a dimensão da Reforma Psiquiátrica se não conhecer, por exemplo, a gigantesca área física da antiga colônia e a maneira como era usada e como é hoje em dia. Vi que o indivíduo era considerado doente, não possuindo vínculo social, vivia em um ambiente fechado, em condições precárias de vida. Atualmente, com a proposta da Reforma Psiquiátrica, tive a oportunidade de observar no Museu da Loucura, a verdadeira terapêutica, com um propósito definido, de desinstitucionalização. O tratamento hoje é voltado para a socialização com atividades terapêuticas que possam integrar o indivíduo na sociedade, desenvolvendo seu potencial e atendendo as diferenças individuais." (DSC3)
\end{abstract}

O modelo manicomial era realizado em instituições fechadas, baseada na custódia, tutela, vigilância e disciplina, que promoviam o isolamento e segregação das pessoas. A Psiquiatria Tradicional do modelo asilar atuava sobre a doença e tinha como objetivo a cura, com a Reforma Psiquiátrica novos conceitos e olhares constroem outros modos de entendimento sobre a loucura, consequentemente, promovem práticas diferenciadas.

"A parte mais significativa da visita ao Museu da Loucura foi a sala de exposição dos materiais usados para o tratamento do doente mental, como os aparelhos de eletrochoque, as seringas, a grade das celas, e as fotos mostrando os pacientes enclausurados, pois proporcionou uma observação da realidade vivenciada pelos alienados naquela época, o que me trouxe muita angústia ao me fazer refletir e tentar imaginar os sofrimentos que muitas pessoas viveram, formas desumanizadas como também observou Basaglia na visita a Barbacena.

Outra parte interessante do museu é uma sala que simula um bloco cirúrgico pois a maneira como as radiografias são mostradas, a música de fundo com os sons de um coração, os instrumentais cirúrgicos que se utilizavam para fazer as lobotomias, enfim o clima que a sala proporciona nos deixa chocados com a maneira como era tratada a loucura." (DSC10)

\section{Dimensão jurídico-política}

No campo das políticas públicas já foram aprovadas várias portarias, resoluções e leis voltadas para a implantação do projeto da Reforma Psiquiátrica, em instancias municipais, estaduais e federais (BRASIL, 2002).

"O Museu da Loucura testemunha a história dos métodos de tratamento adotados pela Psiquiatria, quando nos deparamos com a realidade exposta no museu cria-se uma expectativa de mudanças concretas e duradouras que valorizem o ser humano acima de tudo, mudanças que com a Lei da autoria do Deputado Paulo Delgado, que prevê a extinção progressiva dos manicômios, começa a tomar forma". (DSC5)

Como conseqüência, as mudanças políticas no rumo da saúde mental ampliam o debate sobre a situação dos pacientes psiquiátricos internados nas instituições manicomiais, ameaçando interesses de diversos setores da sociedade.

"Na visita tivemos a oportunidade de
compreender melhor como a vida política,
social e econômica de nosso estado influenciou
na História da Psiquiatria, isso cria alguns
questionamentos dentro de nós, que nos leva a
refletir sobre o nosso papel enquanto cidadãos,
estudantes e futuros profissionais da saúde".
(DSC4)

\section{Dimensão sóciocultural}

A Reforma Psiquiátrica ao produzir um novo espaço social para os indivíduos considerados loucos, objetiva transformar o imaginário social, isto é, as representações, os pré-conceitos que a sociedade tem sobre a loucura, para tanto é preciso transportar a loucura para fora dos muros institucionais, promovendo mudanças no interior da sociedade, revendo valores e crenças excludentes e estigmatizantes. 
"Eu recomendaria a visita ao Museu da Loucura de pessoas que como eu viviam o estigma da loucura concordando com a institucionalização do paciente e que interpretam o "louco" como um perigo para a sociedade, que possuem o pensamento que eles devem ficar isolados da sociedade.

$\mathrm{Na}$ verdade a recomendação seria para todos: crianças, jovens, adultos, idosos, estudantes, profissionais de saúde, políticos, pois através do conhecimento pode-se contribuir para a não marginalização e o não preconceito mantidos em relação aos portadores de sofrimento mental, e desta forma proporcionar adesão dos visitantes como membros essenciais na tolerância de qualquer doente mental". (DSC7)

No processo da Reforma Psiquiátrica pretendese demonstrar como é possível as pessoas consideradas loucas assumirem diversos papéis na sociedade, ou seja, o portador de sofrimento mental passa a ser reconhecido por suas habilidades reais e como sujeito de direito, evitando o peso de assumir unicamente o papel de "doente mental", assim ele deve ser reconhecido socialmente acima de tudo como indivíduo, sendo respeitadas as suas diferenças.

"A parte mais interessante do Museu da Loucura são as fotos de cada interno ou exinterno individualmente, pois através da expressão facial parece nos falar e demonstrar o que sentem, pois é uma forma de mostrar que cada um é indivíduo com sua particularidade, com sua necessidade diferente do outro. São impactantes, pareciam ter vida e alguns olhares ocultamente chamavam por afetividade.

Foi uma forma que o Museu encontrou de mostrar a individualidade e a importância de cada paciente, além do mais também transmite o estado dos pacientes cronificados, que são seres humanos mas que expressam semblantes sofridos, tristes e miseráveis, muito devido a anos de isolamento, descaso e perda da autonomia e auto-estima, que pararam de viver e passaram a sobreviver numa sobrevivência cruel." (DSC8)

\section{CONCLUSÃO}

A vivência acadêmica de visitar o Museu da Loucura em Barbacena, no estado de Minas Gerais, possibilita a aprendizagem das dimensões da Reforma Psiquiátrica ao conduzir o aluno ao questionamento das práticas e saberes da Psiquiatria Tradicional do paradigma asilar, por tal motivo a visita é uma experiência mobilizadora, pois o Museu da Loucura é um espaço onde a arte, a história e a memória se organizam para resgatar e preservar fragmentos da psiquiatria mineira, revelando através da exibição de equipamentos, acervo do hospital e documentações de dados coletados e pesquisados, em todo o Estado de Minas Gerais, as abissais diferenças entre as práticas e saberes da psiquiatria do início do século passado e a abordagem atual do portador de sofrimento mental, assim do alto do torreão do Museu não é possível que o passado, tempo de horrores, seja esquecido. Além de que tal proposta em sintonia com o Projeto Político Pedagógico do Curso de Graduação em Enfermagem da PUC Minas - Betim ao proporcionar diversificação dos cenários da aprendizagem e atores envolvidos no processo pode contribuir para a formação de profissionais enfermeiros com compromisso social, visão ética e humanística, críticos e reflexivos e sensibilizados com os pressupostos da Reforma Psiquiátrica Brasileira.

\section{REFERÊNCIAS BIBLIOGRÁFICAS}

AMARANTE, P. Loucura, cultura e subjetividade: conceitos e estratégias, percursos e atores da reforma psiquiátrica brasileira. In: FLEURY, S. (Org.). Saúde e Democracia: a luta do CEBES. São Paulo: Lemos Editora, 1997. p.163-185.

BRASIL. Ministério da Saúde. Secretaria Executiva. Legislação em Saúde Mental 1990-2002. $3^{\mathrm{a}}$ ed. Revista e atualizada. Brasília: Ministério da Saúde, 2002.

CHAUÍ, M. Convite à filosofia. São Paulo: Editora Ática, 1994.

COSTA-ROSA, A. O modo psicossocial: um paradigma das práticas substitutivas ao modo asilar. In: AMARANTE, P. (Org.). Ensaios-subjetividade, saúde mental e sociedade. Rio de Janeiro: FIOCRUZ, 2000. p. 141-168.

GERMANO, R. M. O ensino de enfermagem em tempos de mudança. Rev. Bras. Enferm., v. 56, n. 4, p. 365-368, 2003.

JORGE, M. S. B., SILVA, W. V. Paradigmas da enfermagem em saúde mental para o terceiro milênio. In: JORGE, M. S. B., SILVA, W. V., OLIVEIRA, F. B. Saúde mental: da prática psiquiátrica asilar ao terceiro milênio. São Paulo: Lemos, 2000:

LEFÉVRE, F., LEFÉVRE, A. M. C. Os novos instrumentos no contexto da pesquisa qualitativa. In: LEFÉVRE, F. LEFÉVRE, A. M. C., TEIXEIRA, J. J. (Org.). O discurso do sujeito coletivo: uma nova abordagem metodológica em pesquisa qualitativa. Caxias do Sul: EDUCS, 2000. p. 11-35.

MINAYO, M. C. S. Ciência, técnica e arte: o desafio da pesquisa social. In: ___ (Org.). Pesquisa social: Pesquisa social: teoria, método e criatividade. Petrópolis: Vozes, 1999. p. 9-29.

ROTELLI, F., AMARANTE, P. Reformas Psiquiátricas na Itália e no Brasil: aspectos históricos e metodológicos. In: BEZERRA, JR., B, AMARANTE, P. (Org.) Psiquiatria sem hospício. Rio de Janeiro: Relume-Dumará, 1992. p. 41-55. 
BOTTI, Nadja Cristiane Lappann; Cotta, Eline Mascarenhas; CÉLIO, Fabiano de Almeida. VISITA AO MUSEU DE LOUCURA: UMA EXPERIÊNCIA DE APRENDIZAGEM SOBRE A REFORMA PSIQUIÁTRICA. Revista Eletrônica de Enfermagem, v. 08, n. 01, p. 52 - 57, 2006. Disponível em http://www.fen.ufg.br/revista/revista8 1/original 06.htm

SILVA FILHO, JF; LEIBING, AG. A Psiquiatria, sua história e seu futuro no Brasil. In: ALBUQUERQUE, P.; LIBÉRIO, M. Práticas ampliadas em saúde mental: desafios e construções do cotidiano. Rio de Janeiro: IPUB/UFRJ, 1999. p.13.

Texto recebido em 25/12/2005

Publicação aprovada em 30/04/2006 